MaPan: Jurnal Matematika dan Pembelajaran

p-ISSN: 2354-6883 ; e-ISSN: 2581-172X

Volume 6, No 1, June 2018 (274-288)

DOI: https://doi.org/10.24252/mapan.2018v6n1a12

\title{
PENGEMBANGAN JIMATH SEBAGAI MULTIMEDIA PEMBELAJARAN MATEMATIKA BERBASIS ANDROID UNTUK SISWA SEKOLAH MENENGAH ATAS
}

\author{
Muhammad Ardiansyah Hendriawan1), Guntur Maulana Muhammad²) \\ 1,2Universitas Suryakancana \\ 1,2Jl. Dr. Muwardi Komplek Pasir Gede Raya Cianjur 43216 Telp/Fax. (0263) 262284 \\ E-mail: ardimbee10@gmail.com ${ }^{1}$, guntur@unsur.ac.id $\left.{ }^{2}\right)$
}

Submitted: 17-07-2018, Revised: 30-10-2018, Accepted: 31-12-2018

\begin{abstract}
Abstrak:
Telepon pintar dapat digunakan untuk berbagai fungsi, salah satunya adalah multimedia pembelajaran. Akan tetapi, masih sangat jarang pengguna telepon pintar bersistem operasi Android khususnya siswa SMA yang menggunakan telepon pintarnya sebagai multimedia pembelajaran. Penelitian ini bertujuan untuk mengembangkan multimedia pembelajaran matematika berbasis Android dengan nama JiMath untuk siswa SMA dan untuk mengetahui respon siswa serta tingkat efektivitas dari multimedia pembelajaran matematika yang dikembangkan. Subjek uji coba sekaligus sasaran dalam penelitian ini adalah siswa kelas X IPA 6 SMAN 2 Cianjur yang berjumlah 32 orang siswa. Metode yang digunakan adalah penelitian dan pengembangan (Research and Development) dengan model pengembangan ADDIE (Analysis, Design, Development, Implementation, and Evaluation). Hasil penelitian menunjukkan bahwa multimedia pembelajaran matematika berbasis Android yang dikembangkan menurut ahli media memenuhi kategori Sangat Layak dengan persentase mencapai $81 \%$, sedangkan menurut ahli materi memenuhi kategori Layak dengan persentase mencapai 65,83\%. Kemudian untuk efektivitas multimedia pembelajaran yang dikembangkan menurut responden memenuhi kategori Layak dengan persentase mencapai $74,1 \%$, sehingga multimedia pembelajaran matematika berbasis Android ini efektif digunakan sebagai multimedia penunjang belajar untuk siswa yang dapat digunakan kapan pun dan dimana pun.
\end{abstract}

Kata Kunci: Multimedia Pembelajaran Matematika, Android, JiMath, ADDIE

\section{DEVELOPMENT OF JIMATH AS THE MULTIMEDIA OF MATHEMATIC EDUCATION BASED ON ANDROID FOR SENIOR HIGHSCHOOL STUDENTS}

\begin{abstract}
:
The smart phone can be used for various functions, one of which is multimedia of education. However, it is still very rare for smart phone users with Android operating system especially high school students who use their smartphones as multimedia of education. This study aims to develop multimedia of mathematics education based on Android with the name JiMath for high school students and to determine the response of students and the level of effectiveness of the multimedia education mathematics developed. The subjects of the experiments as well as the
\end{abstract}


targets in this study were the students of class X IPA 6 SMAN 2 Cianjur which amounted to 32 students. The method used is research and development with ADDIE development model (Analysis, Design, Development, Implementation, and Evaluation). The result of the research shows that the multimedia of mathematics education based on android developed by the media expert meets the Very Eligible category with the percentage reaching 81\%. Meanwhile, according to the material expert meets the Eligible category with a percentage of $65.83 \%$. Then for the effectiveness of multimedia education developed according to respondents meet the Eligible category with the percentage reached $74.1 \%$, so that the multimedia of mathematics education based on Android is effectively used as a supporting multimedia of education for students who can use anytime and anywhere.

Keywords: Multimedia of Mathematics Learning, Android, JiMath, ADDIE

How to Cite: Hendriawan, M. A., \& Muhammad, G. M. (2018). Pengembangan JiMath sebagai Multimedia Pembelajaran Matematika Berbasis Android untuk Siswa Sekolah Menengah Atas. MaPan: Jurnal Matematika dan Pembelajaran, 6(2), 274-288.

\section{PENDAHULUAN}

Pendidikan merupakan kebutuhan manusia sepanjang hayat. Hal ini menjadikan pendidikan sangat penting, karena tanpa pendidikan manusia akan sulit untuk berkembang. Tujuan pendidikan adalah mencerdaskan kehidupan bangsa dan mengembangkan manusia seutuhnya. Dengan demikian pendidikan harus benar - benar diarahkan untuk menghasilkan manusia yang berkualitas dan mampu bersaing, di samping memiliki budi pekerti luhur dan moral yang baik.

Pada era modern ini, perkembangan teknologi dan informasi sudah sangat berkembang dengan pesat dan tidak bisa dihindari lagi pengaruhnya terhadap dunia pendidikan, baik itu pengaruh yang positif ataupun pengaruh yang negatif, sehingga menuntut dunia pendidikan untuk senantiasa menyesuaikan dengan perkembangan teknologi terhadap upaya peningkatan mutu pendidikan, terutama dalam hal memanfaatkan penggunaan teknologi dan informasi bagi dunia pendidikan khususnya dalam proses belajar mengajar (Sutopo, 2012).

Banyak cara yang telah diupayakan untuk meningkatkan mutu pendidikan diantaranya adalah pengembangan atau pembaharuan kurikulum, metode atau model pembelajaran, media atau multimedia pembelajaran, ataupun pengembangan kualitas pendidik. Dari sekian banyaknya upaya tersebut yang menarik untuk dikembangkan dan berhubungan dengan teknologi adalah media atau multimedia pembelajaran. 
Menurut Daryanto (2013), multimedia terbagi menjadi dua kategori, yaitu: multimedia linier dan multimedia interaktif. Multimedia linier adalah suatu multimedia yang tidak dilengkapi dengan alat pengontrol yang dapat dioperasikan oleh penggunaan seperti TV dan film. Sedangkan multimedia interaktif adalah suatu multimedia yang dilengkapi dengan alat pengontrol, sehingga pengguna dapat memilih apa yang dikehendaki untuk proses selanjutnya, seperti pembelajaran interaktif, aplikasi game, dan lain - lain.

Arsyad (2013) mendefinisikan multimedia berupa kombinasi antara teks, grafik, animasi, suara, dan video. Definisi sederhana ini telah pula mencakup salah satu jenis kombinasi yang diuraikan pada bagian terdahulu, misalnya kombinasi slide dan tape audio. Namun, pada bagian ini perpaduan dan kombinasi dua atau lebih jenis media ditekankan kepada kendali komputer sebagai penggerak keseluruhan gabungan media itu. Dengan demikian multimedia adalah berbagai macam kombinasi grafik, teks, suara, video, dan animasi.

Sedangkan menurut Vaughan dalam Rukimin (2015), mengatakan bahwa multimedia merupakan kombinasi antara teks, seni, suara, animasi, dan video yang disampaikan melalui komputer atau peralatan elektronik dan digital. Jika menggunakan bersama-sama elemen multimedia tersebut seperti gambar dan animasi yang dilengkapi dengan suara video clip, dan informasi dalam bentuk teks, maka akan dapat memberikan makna yang jelas kepada orang yang memerlukannya.

Fungsi media atau multimedia di dalam proses pembelajaran cukup penting dalam meningkatkan kualitas proses pembelajaran, terutama membantu siswa untuk belajar. Selain itu, media pembelajaran juga dapat meningkatkan minat belajar siswa karena dirancang semenarik dan seefektif mungkin yang disesuaikan dengan keadaan siswa pada saat pembelajaran sehingga proses pembelajaran menjadi lebih menyenangkan.

Menurut Kemp dan Dayton dalam Nugrawiyati (2018), media atau multimedia pembelajaran juga memiliki kontribusi terhadap pengembangan dan peningkatan pembelajaran sebagai berikut: (1) penyampaian pesan pembelajaran dapat lebih terstandar, (2) pembelajaran dapat lebih menarik, (3) pembelajaran menjadi lebih interaktif, (4) waktu pelaksanaan pembelajaran dapat efisien, (5) kualitas pembelajaran dapat ditingkatkan, (6) proses pembelajaran dapat berlangsung kapan pun dan di mana pun diperlukan, (7) sikap positif siswa terhadap materi serta proses pembelajaran dapat ditingkatkan, dan (8) peran guru berubah ke arah yang positif. 
Selain kontribusi yang dimiliki oleh media atau multimedia pembelajaran, terdapat pula manfaat-manfaat yang dimiliki multimedia. Menurut Hattu, Widyastuti, dan Sholeh (2015), manfaat-manfaat yang dimiliki oleh multimedia antara lain adalah: (1) multimedia menjadikan pemakai lebih mudah dan cepat dalam mempelajari suatu aplikasi, (2) multimedia menjadikan suatu aplikasi lebih hidup karena pengguna dapat berinteraksi dengan sistem secara langsung, (3) multimedia menjadikan aplikasi lebih menarik karena dapat memberikan suatu hiburan, (4) multimedia memberi lebih banyak pilihan dalam menyampaikan informasi sehingga jika salah satu saluran informasi terputus, orang masih dapat menggunakan saluran informasi lainnya.

Dalam pembelajaran, penggunaan teknologi pada saat ini sudah bukan hal baru lagi bagi guru dan siswa. Dengan berkembangnya teknologi, guru dapat memberikan pelayanan pendidikan tanpa harus bertatap muka dengan siswa. Sedangkan untuk siswa, diberikan kemungkinan untuk berinteraksi, mengeksplorasi, dan mengakses sumber belajar secara fleksibel tanpa terbatas waktu dan tempat melalui penggunaan berbagai macam media seperti komputer atau bahkan telepon pintar. Dengan demikian baik guru ataupun siswa dituntut untuk dapat menggunakan dan memanfaatkan teknologi dalam pembelajaran.

Sebagai fasilitator, peran guru dalam memberikan pelayanan pendidikan adalah untuk memudahkan siswa dalam proses pembelajaran serta guru juga dituntut untuk dapat mengikuti perkembangan teknologi yang memungkinkan setiap guru dapat menggunakan, memanfaatkan dan mengembangkan berbagai pilihan media yang dianggap cocok dalam rangka meningkatkan proses pembelajaran. Hal ini jelas menunjukkan bahwa penggunaan dan pengembangan teknologi berupa media atau multimedia pembelajaran yang dilakukan oleh guru merupakan hal yang penting dalam proses pembelajaran.

Sundayana (2013) mengemukakan bahwa kriteria utama dalam pemilihan multimedia pembelajaran yang cocok adalah ketepatan tujuan pembelajaran, yang artinya dalam menentukan multimedia yang akan digunakan pertimbangannya bahwa multimedia tersebut harus dapat memenuhi kebutuhan atau mencapai tujuan yang inginkan. Beberapa hal yang harus diperhatikan dalam pemilihan multimedia pembelajaran ini, antara lain: (1) dukungan terhadap isi bahan pelajaran, (2) kemudahan dalam memperoleh multimedia yang akan digunakan, (3) keterampilan guru dalam menggunakannya, (4) tersedia waktu untuk menggunakannya, (5) sesuai dengan taraf berpikir siswa. 
Selaras dengan yang diungkapkan oleh Sundayana, Sungkono (2008) mengemukakan bahwa hal-hal yang perlu dipertimbangkan dalam pemilihan multimedia pembelajaran yang cocok adalah sebagai berikut: (1) tujuan pembelajaran, (2) keefektifan, (3) siswa, (4) ketersediaan, (5) kualitas teknis, (6) biaya pengadaan, (7) fleksibilitas, (8) kemampuan orang yang menggunakannya, (9) alokasi waktu.

Namun demikian, penggunaan dan pengembangan teknologi dalam dunia pendidikan masih berjalan relatif lambat jika dibandingkan dengan perkembangan teknologi informasi dan komunikasi. Sampai saat ini, masih banyak ditemui proses pembelajaran yang di dalamnya terdapat seorang guru berdiri sebelah papan tulis di depan ruang kelas, sementara itu sejumlah siswa dengan menggunakan seragam duduk rapi di bangku masing-masing, dengan buku ajar atau buku catatan. Kondisi tersebut dapat dikatakan sebagai proses pembelajaran konvensional.

Teknologi informasi dan komunikasi mengubah lokasi belajar dari kelas ke tempat di mana saja dan kapan saja siswa dapat belajar, hal ini selaras dengan yang diungkapkan oleh Rosenberg dalam Kustini dan Nurkhin (2011) yaitu: (1) pergeseran dari pelatihan ke penampilan, (2) pergeseran dari ruang kelas ke di mana dan kapan saja, (3) pergeseran dari kertas ke "online" atau saluran, (4) pergeseran dari fasilitas fisik ke fasilitas jaringan kerja, dan (5) pergeseran dari siklus waktu ke waktu nyata. Kelima pergeseran yang dituliskan sangat identik dengan media atau multimedia pembelajaran. Oleh karena itu, media atau multimedia pembelajaran merupakan hal penting untuk dikembangkan.

Media atau multimedia pembelajaran yang perlu dikembangkan dan sesuai dengan perkembangan teknologi informasi dan komunikasi yaitu multimedia pembelajaran berbasis Android yang terdapat pada telepon pintar. Android adalah sebuah sistem operasi perangkat mobile berbasis Linux yang dirancang untuk perangkat bergerak layar sentuk seperti telepon pintar dan komputer tablet. Berdasarkan survei Internasional Data Corporation di tahun 2016 sekitar 86,8\% telepon pintar menggunakan sistem operasi Android. Kemudian data eMarketer, pengguna telepon pintar di Indonesia akhir 2015 tercatat 55 juta dan diperkirakan pada 2016 akan ada 65,2 juta dan pada tahun 2017 akan ada 74,9 juta pengguna telepon pintar. Mayoritas pengguna telepon pintar di Indonesia berdasarkan survei oleh Taylor Nelson Sofrens (TNS) adalah remaja dengan umum sekitar 16 - 21 tahun (Jose, 2015).

Telepon pintar tersebut dapat digunakan untuk berbagai macam fungsi, salah satunya adalah media pembelajaran. Akan tetapi, masih sangat jarang 
pengguna telepon pintar bersistem operasi Android khususnya siswa SMA yang menggunakan telepon pintarnya sebagai media pembelajaran. Kebanyakan dari aplikasi yang sering digunakan oleh pengguna telepon pintar adalah aplikasi hiburan, seperti media sosial, permainan, musik, kamera, dan lain sebagainya.

Pada saat ini sudah banyak guru ataupun masyarakat yang sudah mengembangkan Android sebagai multimedia pembelajaran, namun sayangnya produk media pembelajaran berbasis Android tersebut belum dipublikasikan ke khalayak umum seperti diunggah ke Google Playstore dan jika ditemukan produk media pembelajaran matematika berbasis Android masih berbayar atau tidak gratis.

Menurut survei yang dilakukan oleh peneliti pada 28 Juli 2017 di Google Playstore mengenai media pembelajaran matematika berbasis Android, sudah terdapat beberapa aplikasi media pembelajaran matematika di Google Playstore tersebut yang gratis untuk diunduh, namun sayangnya beberapa konten di dalamnya tidaklah gratis atau masih berbayar. Maka menurut survei tersebut, peneliti yakin bahwa tidak ada multimedia pembelajaran matematika berbasis Android yang benar - benar seluruh kontennya bisa di dapatkan secara gratis atau cuma-cuma (Wikipedia, 2017).

Berdasarkan uraian tersebut, maka peneliti tertarik untuk mengembangkan multimedia pembelajaran matematika berbasis Android ini dan melaksanakannya dalam penelitian yang berjudul: "Pengembangan JiMath sebagai Multimedia Pembelajaran Matematika Berbasis Android untuk Siswa Sekolah Menengah Atas".

\section{METODE PENELITIAN}

Penelitian ini dilaksanakan di sekolah SMAN 2 Cianjur. Metode yang digunakan dalam penelitian ini adalah penelitian dan pengembangan (Research and Development), dengan model pengembangan yaitu ADDIE (Analysis, Design, Development, Implementation, and Evaluation).

Subjek pelaku dalam penelitian ini adalah peneliti sekaligus pengembang multimedia pembelajaran. Subjek uji coba ahli materi dan ahli media dalam penelitian ini adalah dosen Pendidikan Matematika FKIP Universitas Suryakancana yang masing-masing berjumlah 3 orang. Sedangkan subjek uji coba sekaligus sasaran dalam penelitian ini adalah siswa kelas X IPA 6 SMAN 2 Cianjur yang berjumlah 32 orang siswa. 
Instrumen yang digunakan dalam penelitian ini berupa instrumen non tes. Instrumen non tes dalam penelitian ini berupa kuesioner atau angket yang diukur dengan skala Likert. Kuesioner atau angket yang digunakan berisi pertanyaan atau pernyataan yang diberikan kepada ahli media, ahli materi, dan siswa untuk mengetahui tingkat efektivitas dari multimedia pembelajaran matematika yang dikembangkan. Tipe jawaban yang digunakan adalah berbentuk Checklist.

Prosedur penelitian ini terdiri dari lima tahap, yaitu: (1) tahap analisis yaitu untuk mendapatkan informasi mengenai kebutuhan yang digunakan dalam pengembangan multimedia pembelajaran, (2) tahap desain yaitu perancangan desain produk atau multimedia pembelajaran yang meliputi desain layout, letak menu, dan tombol navigasi, (3) tahap pengembangan yaitu dilakukannya pembuatan dan penggabungan konten yang sudah dirancang atau didesain dengan menggunakan program Android Studio, pada tahap ini juga dilakukan pengujian oleh para ahli, (4) tahap implementasi yaitu pengujicobaan produk atau multimedia pembelajaran kepada pengguna telepon pintar di SMAN 2 Cianjur, (5) tahap penilaian yaitu evaluasi dari pengembangan multimedia pembelajaran matematika yang dikembangkan.

\section{HASIL PENELITIAN DAN PEMBAHASAN \\ Deskripsi Hasil Pengembangan}

Multimedia pembelajaran matematika yang dikembangkan dalam penelitian ini berbentuk aplikasi Android dengan format apk yang bisa dipasang di telepon pintar dan sekarang sudah bisa diunduh di Google Playstore dengan kata kunci pencarian JiMath. Multimedia pembelajaran ini dikembangkan dengan menggunakan program Android Studio melalui model pengembangan ADDIE (Analysis, Design, Development, Implementation, and Evaluation). Konten-konten dalam aplikasi JiMath ini terdiri dari materi matematika, latihan soal, kuis, video pembelajaran, sejarah matematika, dan tentang pengembang. Tampilan atau bentuk multimedia pembelajaran matematika berbasis Android ini dapat dilihat pada gambar 1 hingga gambar 6 berikut: 

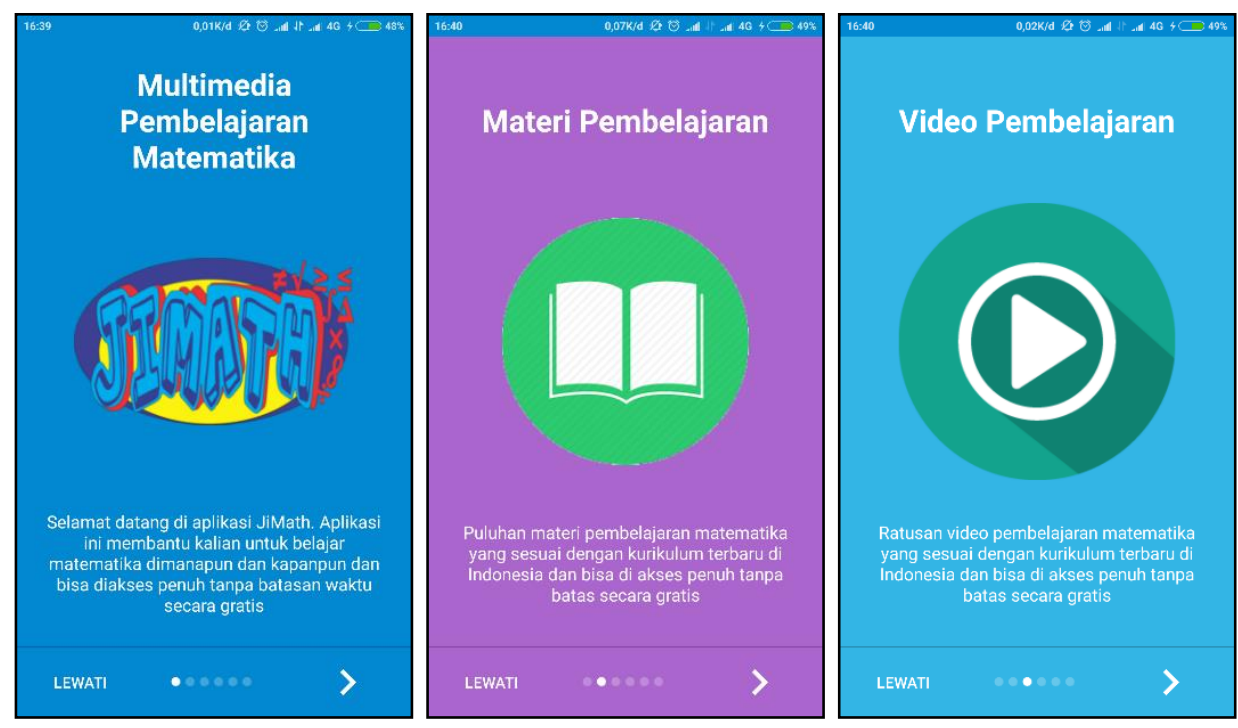

Gambar 1. Tampilan Awal JiMath

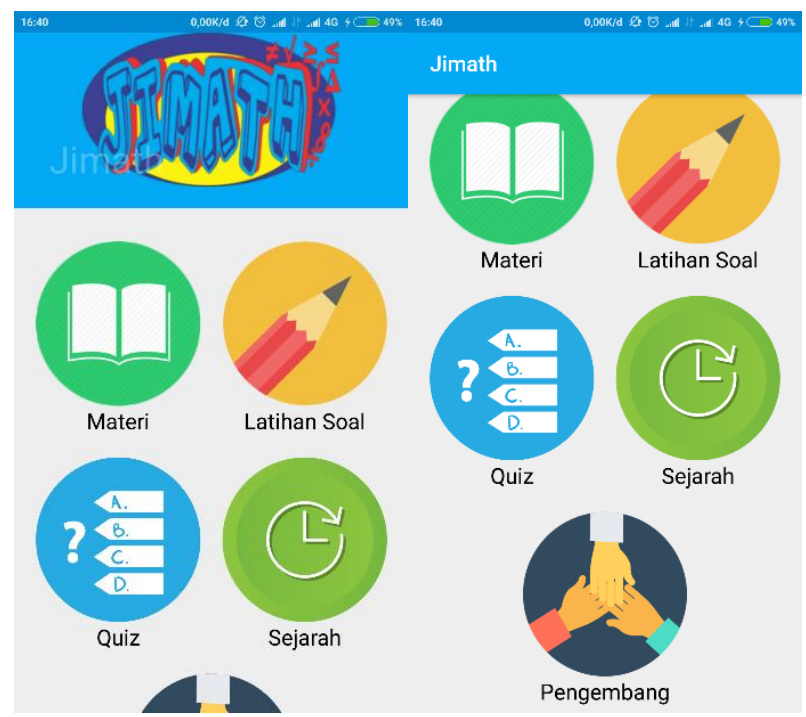

Gambar 2. Tampilan Home 


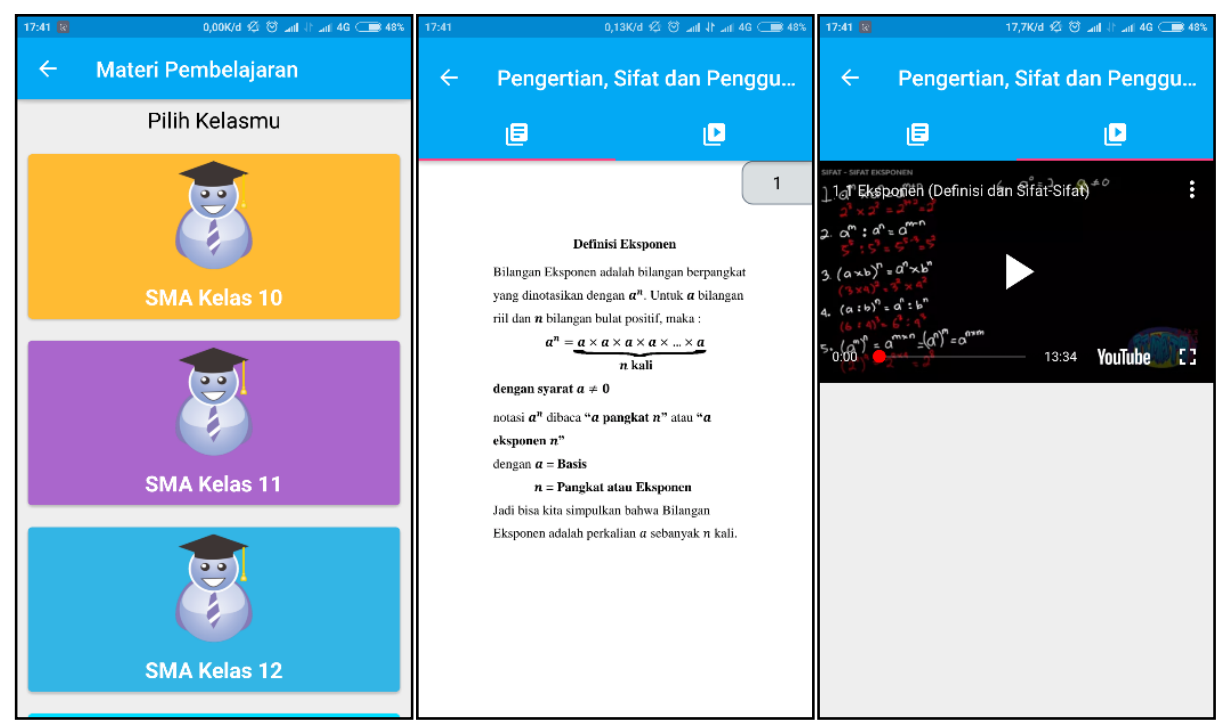

Gambar 3. Tampilan Materi

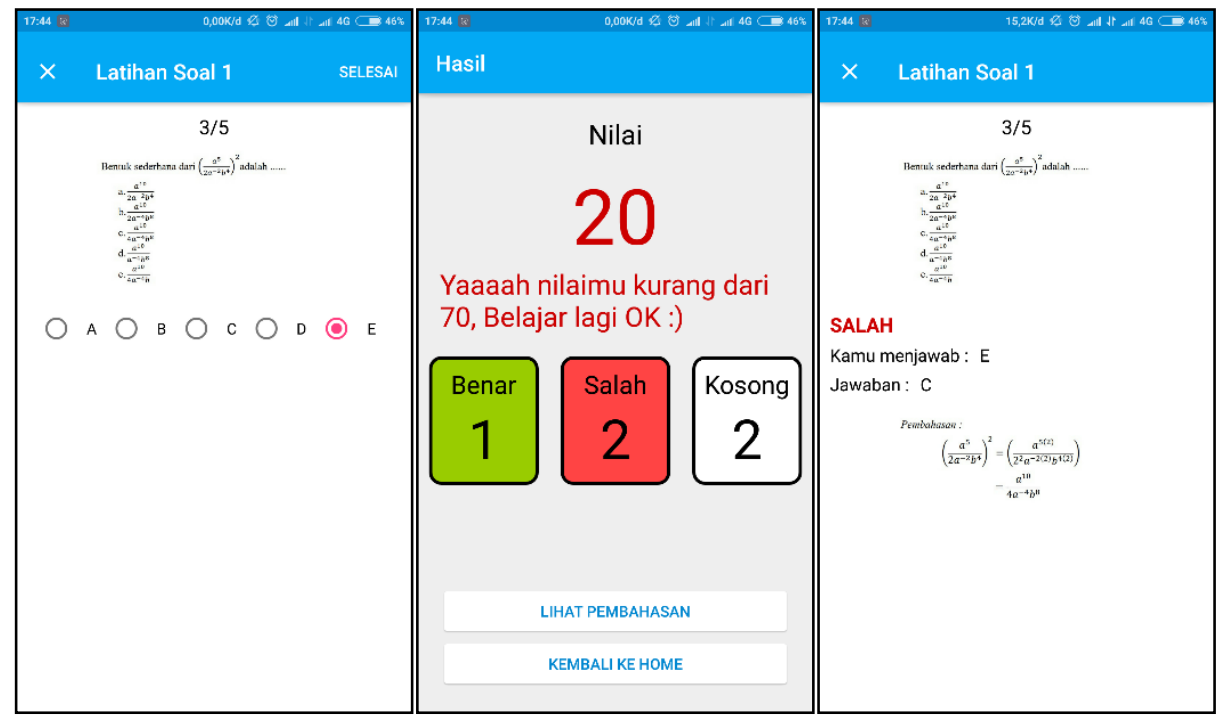

Gambar 4. Tampilan Latihan Soal 


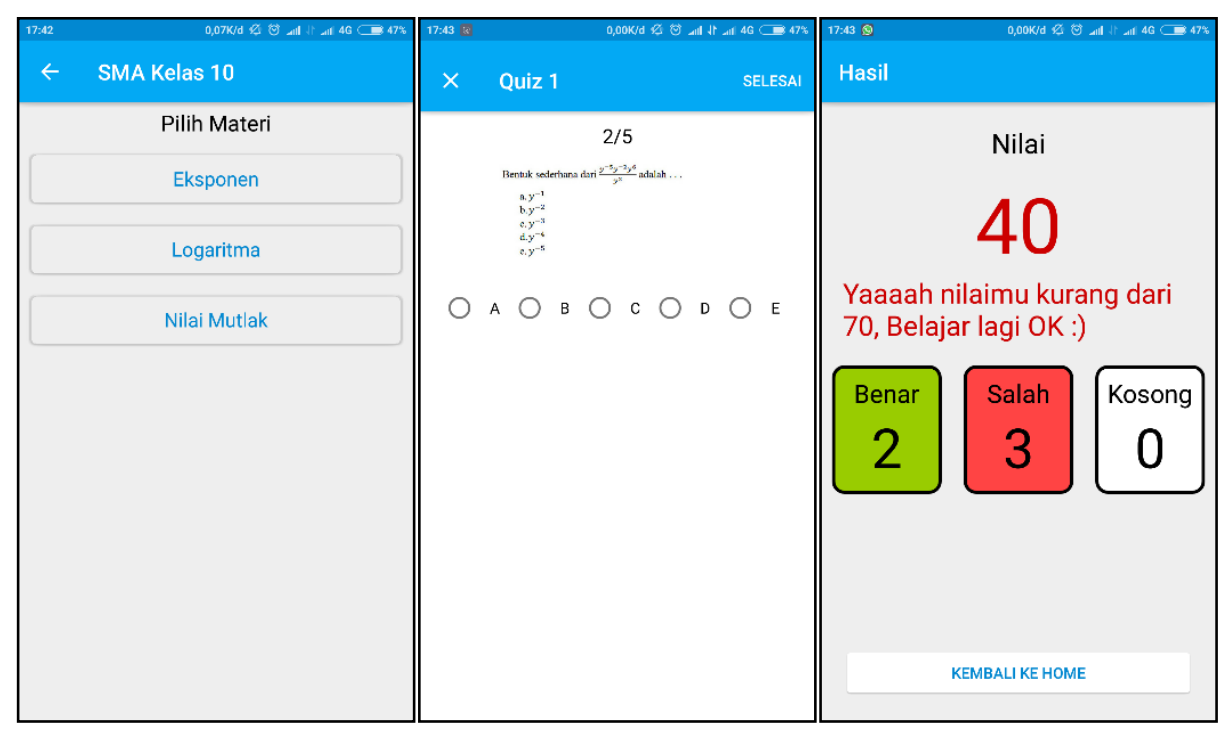

Gambar 5. Tampilan Quiz

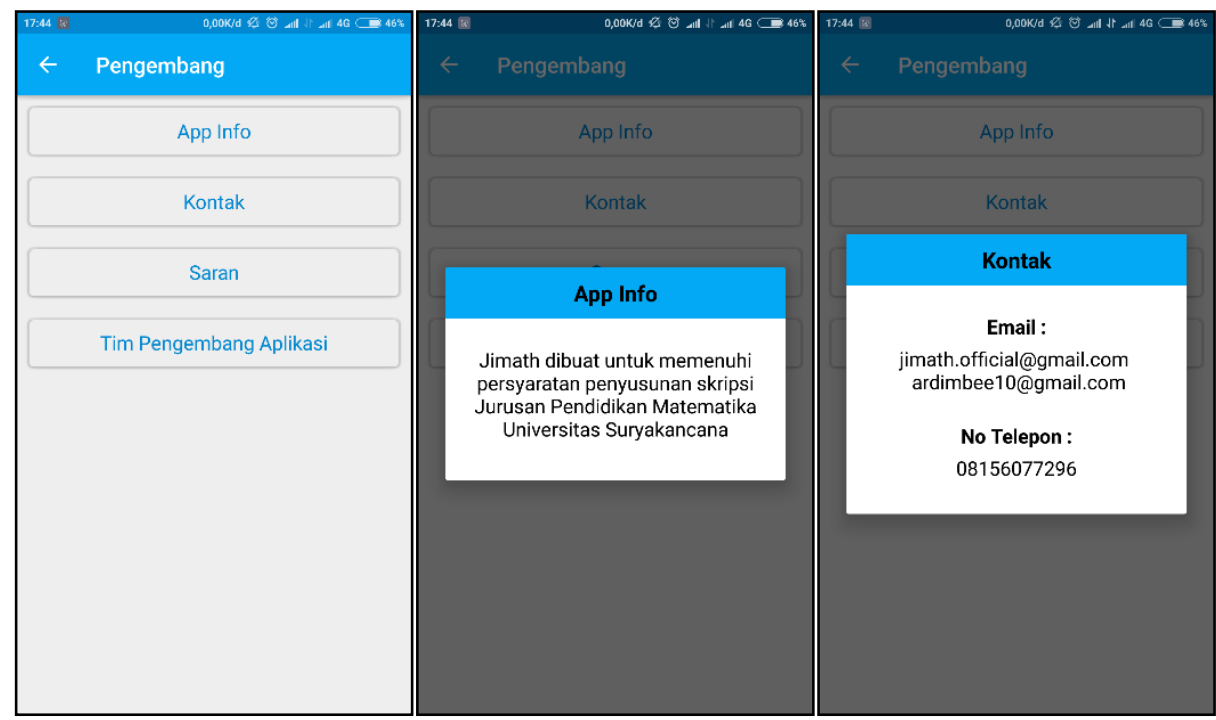

Gambar 6. Tampilan Pengembang

\section{Deskripsi dan Analisis Data Hasil Uji Coba}

Berdasarkan uji coba yang telah dilakukan kepada para ahli, diperoleh hasil penilaian multimedia pembelajaran matematika berbasis Android ini menurut ahli media berdasarkan kualitas instruksional adalah $80 \%$ dan berdasarkan kualitas teknis adalah $82,22 \%$. Jadi secara keseluruhan memenuhi kategori Sangat Layak dengan persentase mencapai $81 \%$, sedangkan hasil penilaian multimedia pembelajaran matematika berbasis Android ini menurut ahli materi berdasarkan kualitas instruksional adalah $69 \%$ dan berdasarkan kualitas isi dan tujuan adalah 63\%. Jadi secara keseluruhan memenuhi kategori 
Layak dengan persentase mencapai $65,83 \%$. Kritik dan saran yang diperoleh dari ahli media dan ahli materi dapat dilihat pada tabel 1.

Tabel 1. Hasil Evaluasi oleh Ahli Media dan Ahli Materi

\begin{tabular}{|c|c|}
\hline Validator & Kritik dan Saran \\
\hline \multirow[t]{5}{*}{ Ahli Media 1} & $\begin{array}{l}\text { Pada laman hasil, perbaiki kotak “Kosong”. Karena } \\
\text { kurang enak dilihat (tidak simetris). }\end{array}$ \\
\hline & $\begin{array}{l}\text { Untuk materi, agar lebih fokus untuk tingkatan. } \\
\text { Perguruan tinggi dapat dipisah menjadi aplikasi sendiri, } \\
\text { atau bahkan dijadikan tiga aplikasi (untuk SMP, SMA, } \\
\text { dan Perguruan Tinggi). }\end{array}$ \\
\hline & $\begin{array}{l}\text { Pada laman materi, "Pilih Materimu” agar dibuat } \\
\text { kebawah untuk mempermudah visualisasi konten - } \\
\text { konten yang tersedia. }\end{array}$ \\
\hline & $\begin{array}{l}\text { Pada materi (dokumen) agar halaman kosong bisa } \\
\text { dikurangi atau diberikan pembatas. }\end{array}$ \\
\hline & $\begin{array}{l}\text { Pada "App Info", keterangan bisa dibuat lebih umum. } \\
\text { Misalnya memberikan manfaat dll. }\end{array}$ \\
\hline \multirow[t]{2}{*}{ Ahli Media 2} & Video diperbanyak. \\
\hline & Dilengkapi isinya. \\
\hline Ahli Media 3 & $\begin{array}{l}\text { JiMath masih sebatas memindahkan materi di buku dan } \\
\text { latihan ke aplikasi, sebaiknya dikembangkan lebih } \\
\text { interaktif, memuat banyak eksplorasi yang dapat } \\
\text { dilakukan siswa. }\end{array}$ \\
\hline \multirow[t]{4}{*}{ Ahli Materi 1} & $\begin{array}{l}\text { Perbanyak contoh dengan variasi soal, serta contoh soal } \\
\text { penggunaan dalam kehidupan nyata (realistik). }\end{array}$ \\
\hline & $\begin{array}{l}\text { Memotivasi bisa dengan pemberian soal dari sangat } \\
\text { mudah sampai sangat sulit. Bisa juga dengan pemberian } \\
\text { reward, atau penambahan sub - sub judul “Tahukah } \\
\text { Kamu” yang menjelaskan penggunaan materi tersebut. }\end{array}$ \\
\hline & Video sudah baik, alangkah baik audionya diperbesar. \\
\hline & Kelengkapan materi ditambah. \\
\hline \multirow[t]{3}{*}{ Ahli Materi 2} & $\begin{array}{l}\text { Pembahasan terlalu kaku atau tidak ada trik - trik } \\
\text { tertentu. }\end{array}$ \\
\hline & Masih seperti ebook. \\
\hline & Konsistensi penulisan masih kurang. \\
\hline \multirow[t]{2}{*}{ Ahli Materi 3} & $\begin{array}{l}\text { Untuk penilaian berikutnya (lebih baik menggunakan } \\
\text { tampilan langsung agar bisa langsung dicoret). }\end{array}$ \\
\hline & $\begin{array}{l}\text { Untuk video harus lebih menarik (berbeda dengan } \\
\text { tampilan materi). }\end{array}$ \\
\hline
\end{tabular}


Setelah dilakukan pengujian dan penilaian atau validasi oleh para ahli, barulah multimedia pembelajaran matematika berbasis Android ini diujicobakan kepada responden yaitu siswa SMAN 2 Cianjur kelas X IPA 6. Berdasarkan uji coba yang telah dilakukan kepada responden, diperoleh hasil penilaian multimedia pembelajaran matematika berbasis Android ini berdasarkan kualitas instruksional adalah 77,3\%, berdasarkan kualitas isi dan tujuan adalah 70,6\% dan berdasarkan kualitas teknis adalah 74,5\%. Jadi secara keseluruhan memenuhi kategori Layak dengan persentase mencapai 74,1\%. Kritik dan saran yang diperoleh dari beberapa responden dapat dilihat pada tabel 2.

Tabel 2. Hasil Respon Siswa

\begin{tabular}{|c|c|}
\hline Subjek Uji Coba & Kritik dan Saran \\
\hline \multirow[t]{4}{*}{ Responden 1} & Perbanyak lagi materinya. \\
\hline & Perbaiki lagi segala kekurangannya. \\
\hline & $\begin{array}{l}\text { Offlinekan videonya, agar bila tidak punya kuota } \\
\text { tetap bisa belajar. }\end{array}$ \\
\hline & Terus tingkatkan dan menjadi yang terbaik. \\
\hline Responden 2 & $\begin{array}{l}\text { Menurut saya aplikasi ini sangat membantu dalam } \\
\text { mempelajari pelajaran matematika karena ada materi, } \\
\text { latihan soal, pembahasan, kuis, dan video juga. } \\
\text { Namun mungkin akan lebih baik jika latihan soalnya } \\
\text { lebih banyak lagi. }\end{array}$ \\
\hline \multirow[t]{3}{*}{ Responden 3} & $\begin{array}{l}\text { Segera lengkapi lagi materi di aplikasinya agar } \\
\text { banyak yang mengunduh dan bisa digunakan oleh } \\
\text { semua kalangan. }\end{array}$ \\
\hline & $\begin{array}{l}\text { Videonya diharapkan tidak online, karena apabila } \\
\text { tidak ada kuota masih bisa belajar. }\end{array}$ \\
\hline & $\begin{array}{l}\text { Tingkatkan lagi agar menjadi yang terbaik di } \\
\text { Indonesia, dan dihargai oleh negara lain. }\end{array}$ \\
\hline Responden 4 & $\begin{array}{l}\text { Saya harap semua materi dapat diperbaharui agar } \\
\text { dapat diakses sepenuhnya. }\end{array}$ \\
\hline \multirow[t]{4}{*}{ Responden 5} & Tolong perbaiki lagi sistem aplikasinya. \\
\hline & Perbanyak lagi pembahasan materinya. \\
\hline & $\begin{array}{l}\text { Tampilannya tolong diubah agar pengguna } \\
\text { khususnya saya tidak merasa bosan. }\end{array}$ \\
\hline & $\begin{array}{l}\text { Sekarang zamannya teknologi, tapi tolong jangan } \\
\text { jadikan teknologi sebagai peran utama dalam } \\
\text { mengajar para siswa. }\end{array}$ \\
\hline
\end{tabular}




\begin{tabular}{cl}
\hline Responden 6 & $\begin{array}{l}\text { Mungkin lebih banyak lagi atau lebih diakses lagi } \\
\text { soal-soalnya, karena yang offline tidak bisa membuka } \\
\text { soalnya. }\end{array}$ \\
\hline Responden 7 & $\begin{array}{l}\text { Lebih ditingkatkan lagi karena dengan dibuatnya } \\
\text { aplikasi ini semoga bisa menjadi solusi pembelajaran } \\
\text { bagi para pelajar. }\end{array}$ \\
\hline Responden 8 & $\begin{array}{l}\text { Jangan pakai kuota dan tampilannya harus lebih } \\
\text { menarik. }\end{array}$ \\
\hline Responden 9 & Semoga selalu sukses. \\
\hline Responden 10 & $\begin{array}{l}\text { Banyak hal yang tidak saya setujui karena memang } \\
\text { dalam pembelajaran matematika harus disukai. } \\
\text { Untuk tampilan menu sudah bagus dan dapat } \\
\text { dipahami namun untuk navigasi mungkin bisa } \\
\text { membingungkan untuk pemilihan materi, lalu size } \\
\text { aplikasinya harap diperkecil dan menyediakan soal - } \\
\text { soal secara offline. }\end{array}$ \\
\hline
\end{tabular}

\section{SIMPULAN}

Berdasarkan hasil penelitian dan pembahasan, secara umum dapat dibuat kesimpulan hasil penelitian yaitu tingkat efektivitas pengembangan JiMath sebagai multimedia pembelajaran matematika berbasis Android ini memenuhi kategori Sangat Layak dengan persentase mencapai 81\% menurut ahli media, lalu memenuhi kategori Layak dengan persentase mencapai 65,83\% menurut ahli materi, sedangkan memenuhi kategori Layak dengan persentase mencapai $70,6 \%$ menurut responden atau siswa. Sehingga multimedia pembelajaran matematika berbasis Android ini efektif digunakan sebagai multimedia penunjang belajar untuk siswa yang dapat digunakan dimanapun dan kapanpun. Selanjutnya, perlu dilakukan pengembangan materi dan video pembelajaran secara keseluruhan sehingga dapat meningkatkan kualitas dari aplikasi JiMath ini, perlu adanya tim khusus untuk mengembangkan aplikasi Android seperti programmer, dan yang terakhir adalah sebagai masalah terbuka, perlu adanya penelitian lanjutan mengenai hasil implementasi JiMath terhadap ragam kemampuan berpikir matematis. 


\section{DAFTAR PUSTAKA}

Arsyad, A. (2013). Media pembelajaran. Jakarta: PT Raja Grafindo Persada.

Daryanto. (2013). Media pembelajaran (perannya sangat penting dalam mencapai tujuan pembelajaran). Yogyakarta: Gava Media.

Hattu, H. M. L., Widyastuti, N., \& Sholeh, M. (2015). Aplikasi tutorial interaktif pelajaran teknologi informasi \& komunikasi SD Caturtunggal III Yogyakarta. Jurnal Script, 2(2). Retrieved from http:/ /id.portalgaruda.org/index.php?ref=browse\&mod=viewarticle\& article $=440772$

Jose, A. (2015). Pengguna smartphone di Indonesia capai 55 juta. Retrieved from https:/ / techno.okezone.com/read/2015/09/19/57/1217340/2015pengguna-smartphone-di-indonesia-capai-55-juta

Kustini, S., \& Nurkhin, A. (2011). Pemanfaatan teknologi informasi dan komunikasi dalam pembelajaran akuntansi (studi empiris pada guru SMK se Kota Semarang). Jurnal Pendidikan Ekonomi Dinamika Pendidikan, 6(1), 84-104. Retrieved from https:/ / media.neliti.com/media/publications/58512-ID-pemanfaatanteknologi-informasi-dan-komu.pdf

Nugrawiyati, J. (2018). Media audio-visual dalam pembelajaran bahasa arab. ElWasathiya: Jurnal Studi Agama, 6(1), 97-111. Retrieved from http:/ / ejournal.kopertais4.or.id/mataraman/index.php/washatiya/art icle/download/3420/2542/

Rukimin, K. (2015). Multimedia interaktif dalam pembelajaran bahasa arab. In Pengembangan ICT dalam Pembelajaran (pp. 102-114). Retrieved from https:/ / media.neliti.com/media/publications/172221-ID-multimediainteraktif-dalam-pembelajaran.pdf

Sundayana, R. (2013). Media pembelajaran matematika (untuk guru, calon guru, orang tua, dan para pecinta matematika). Bandung: Alfabeta.

Sungkono. (2008). Pemilihan dan penggunaan media dalam proses pembelajaran. Majalah Ilmiah Pembelajaran, 4(1), 71-80. Retrieved from https://media.neliti.com/media/publications/222205-pemiliban-danpenggunaan-media-dalam-pro.pdf

Sutopo, A. H. (2012). Teknologi informasi dan komunikasi dalam pendidikan. 
Muhammad Ardiansyah'1), Guntur Maulana Muhammad2)

Yogyakarta: Graha Ilmu.

Wikipedia. (2017). Android (sistem operasi). Retrieved from https://id.wikipedia.org/wiki/Android_(sistem_operasi) 